\title{
Novel approach to antiangiogenic factors in age-related macular degeneration therapy
}

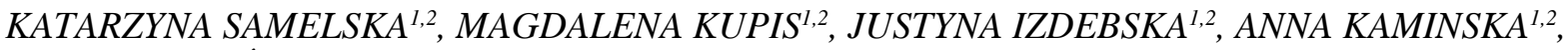 \\ PIOTR SKOPIŃSKR ${ }^{2,3}$
}

${ }^{1}$ Department of Ophthalmology, Medical University of Warsaw, Warsaw, Poland

${ }^{2}$ SPKSO Ophthalmic University Hospital, Warsaw, Poland

${ }^{3}$ Department of Histology and Embryology, Medical University of Warsaw, Warsaw, Poland

\begin{abstract}
Age-related macular degeneration (AMD) is a leading cause of irreversible vision loss among the population above 85 worldwide. There are two main types of AMD: neovascular and dry AMD. Neovascular AMD leads to macular changes resulting from abnormal choroidal neovascularization. Untreated neovascular AMD leads to scar formation and irreversible sight deterioration. Dry AMD in consequence leads to atrophic changes of the macula.

The last decades brought a breakthrough in the therapy of neovascular age-related macular degeneration by introduction of, firstly, photodynamic therapy and, later, anti-VEGF agents administered intravitreally in order to stop neoangiogenesis. However, the treatment of dry AMD is still challenging. Among the directions in dry AMD treatment, the most promising are complement cascade inhibitors and complement cascade targeted gene therapy.

In the article we outline the main directions in up-to-date experimental and practical approaches to wet and dry AMD therapy with the emphasis on antiangiogenic factors and gene therapy focused on the inhibition of pathological angiogenesis.
\end{abstract}

Key words: age-related macular degeneration, axitinib, AMD, eculizumab, gene therapy, brolucizumab, abicipar pegol, faricimab, lampalizumab, pegcetacoplan.

(Cent Eur J Immunol 2022; 47 (1): 117-123)

\section{Introduction}

Age-related macular degeneration (AMD) is a disorder of the macula - the central region of the retina. It is one of the leading causes of irreversible visual impairment. It affects around 3.6 million people worldwide [1]. It is estimated to affect $13.1 \%$ of the population older than 85 years [2].

There are several approaches to AMD classification, including the Three Continent AMD severity scale, which distinguishes 5 stages of the disease: no AMD, mild early, moderate early, severe, and late [2]. Another classification differentiates wet AMD and dry AMD. Wet AMD (or neovascular AMD; nAMD) is an effect of choroidal neovascularization (CNV). In type 1 the changes are located below the retinal pigment epithelium (RPE). In type 2 ("classical choroidal neovascularization") they involve pathological blood vessel formation within the interior layers of the retina. In type 3 the anastomoses between neovascularization and retinal circulations are present. The neovascularization leads to the presence of fluid or hemorrhage in the retinal tissues, retinal pigment epithelial detachments and hard exudates. The irreversible stage of neovascular AMD is subretinal fibrous scar tissue formation [3, 4].

Dry AMD (atrophic AMD) involves outer retinal thinning. The early stage is characterized by accumulation of lipoid extracellular deposits of metabolic products called drusen [5]. Secondary degeneration of the retinal pigment epithelium proceeds and then the degeneration of the choriocapillaris takes place. It manifests as geographic atrophy [3, 4].

Pathological neovascularisation formation is related to imbalance between reactive oxygen species (ROS) and antioxidants. The imbalance leads to oxidative stress and, in consequence, to formation of oxidative stress mediators (e.g. vascular endothelial growth factor - VEGF) by Muller cells and retinal microglia [6, 7].

Vascular endothelial growth factor is an agent produced by hypoxic tissues in order to stimulate vessel growth, as it promotes neovascularization $(\mathrm{NV})$, regulates vascular permeability and, in consequence, triggers the formation of $\mathrm{CNV}$ in nAMD [3]. Due to the introduction of anti-VEGF treatment, the prevalence of blindness due to AMD decreased by almost $30 \%$ from 1990 to 2020 [1]. Anti-VEGF therapy is effective in neovascular AMD, where the patho-

Correspondence: Katarzyna Samelska, MD, Department of Ophthalmology, SPKSO Ophthalmic University Hospital, Poland,

e-mail: samelskakatarzyna@gmail.com

Submitted: 13.10.2021; Accepted: 13.01.2022 
logical angiogenesis is suppressed by VEGF inhibitors. Nowadays, non-exudative AMD has become a challenge for inventing new therapies.

\section{Photodynamic therapy (verteporfin)}

Photodynamic therapy (PDT) with verteporfin is a well-known approach to treat CNV in AMD. Apart from the most common use, which is nAMD, verteporfin therapy is applied in other conditions associated with choroidal pathologies, such as polypoidal choroidal vascularization, central serous chorioretinopathy, and choroidal hemangioma. Its effect is exerted by angioocclusive action of light energy with the presence of a photosensitizer [8-10].

Verteporfin (VP) is a photosensitizer used commonly in ophthalmology. Apart from it, there have been proposed other substances varying in the level of toxicity and affinity to the treated tissues, such as a hematoporphyrin derivative, peptides, and monoclonal antibodies [11].

Photodynamic therapy has also been used in non-ocular conditions such as psoriasis, actinic keratosis and malignancies such as esophageal, lung and skin cancers. The use of verteporfin has been proven successful in choroidal metastases of breast, thyroid, lung and pancreas cancer [12].

Nowadays, the use of PDT in AMD has become less common due to the advances in anti-VEGF treatment.

\section{Advances in anti-VEGF therapy}

Angiogenesis is regulated in multiple mechanisms. VEGFs and their receptors (vascular endothelial growth factor receptors - VEGFRs), as well as placental growth factor (PlGF), angiopoietin 2 (Ang-2), platelet-derived growth factor-B (PDGF-B), vascular endothelial-protein tyrosine phosphatase (VE-PTP) and stromal-derived growth factor (SDF-1) promote angiogenesis secondary to elevation of hypoxia-inducible factor-1 (HIF-1) level upregulation. The subtypes of VEGFRs that are most important for
AMD pathogenesis are VEGFR1 and VEGFR2. VEGFs' main subtypes are VEGF-A and VEGF-B. VEGF-A binds with both VEGFR-1 and VEGFR-2, whereas VEGF-B (as well as PIGF) binds selectively with VEGFR-1 [7].

VEGF leads to vascular leakage and neovascularization $[7,13,14]$. Pathological angiogenesis in eye tissues is induced by VEGF formation in tissues such as retinal pigment epithelium and non-pigmented ciliary epithelium [15].

Anti-VEGF agents are used for treating retinal neovascularization, such as in AMD, diabetic retinopathy and secondary to central retinal vein occlusion. The route of administration is by intra-vitreal injection, which limits the systemic side-effects [13].

Pegaptanib sodium (Macugen; Eyetech Pharmaceuticals/Pfizer) was the first anti-VEGF agent in use for AMD. Pegaptanib binds large-sized VEGF isoforms, such as VEGF165, which limits its effectiveness. The anti-VEGFs clinically approved and currently in use are: bevacizumab (Avastin; Roche), ranibizumab (Lucentis; Novartis), aflibercept (Eylea; Bayer) and brolucizumab (Beovu; Novartis). VEGF-A isoforms of VEGF are bound by bevacizumab and ranibizumab. Bevacizumab is a recombinant humanized monoclonal antibody of VEGF, whose structure contains two light and two heavy chains. It finds its main use in oncology. Ranibizumab is a lightweight humanized monoclonal antibody fragment targeted against VEGF-A isoforms.

Aflibercept is a recombinant protein binding to VEGF-A and VEGF-B isoforms as well as PlGF. It may be administered in an every-2-month regimen. It has been known safe and efficient since 2012 [3, 16].

Brolucizumab is the newest agent approved by the FDA (United States Food and Drug Administration) in 2019. It is a single-chain anti-VEGF-A antibody fragment. Brolucizumab was proven non-inferior to aflibercept in terms of visual function and similar to aflibercept in terms of overall safety in the HAWK and HARRIER trials [17] (Fig. 1, Table 1 [18-29]).

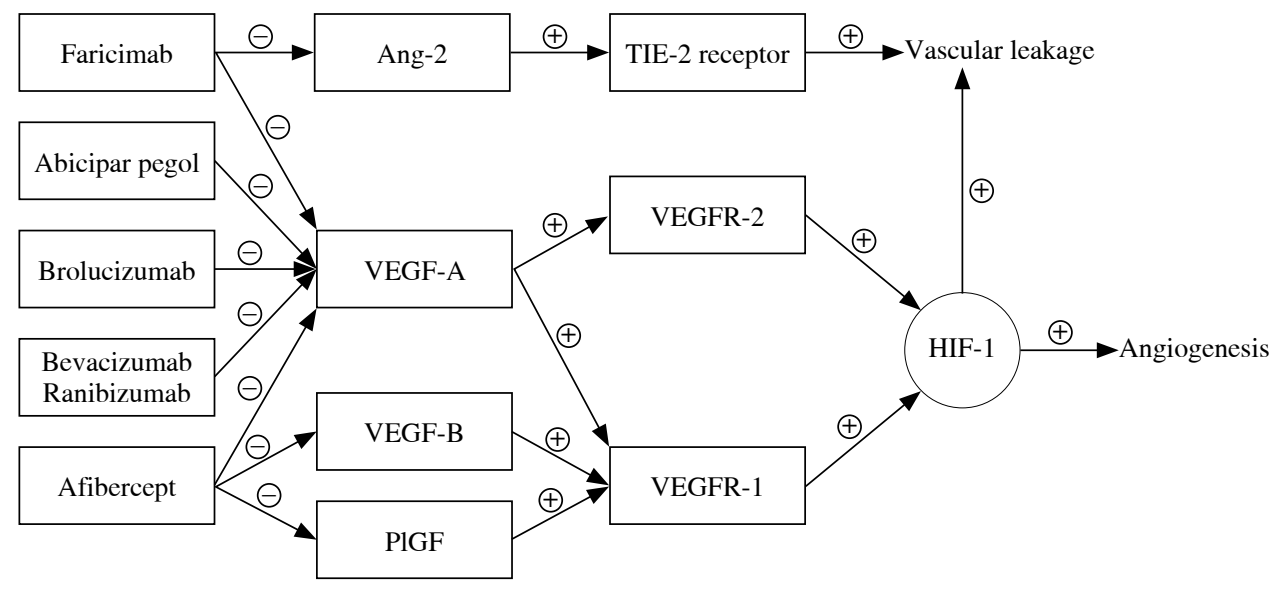

Fig. 1. The targets of anti-VEGF agents and the effect on vascular leakage and angiogenesis 
Table 1. Summary of main characteristics of selected anti-VEGF agents

\begin{tabular}{|c|c|c|c|c|c|}
\hline $\begin{array}{l}\text { Substance name } \\
\text { (commercial name) }\end{array}$ & $\begin{array}{l}\text { Year of FDA } \\
\text { approval }\end{array}$ & Affinity & $\begin{array}{l}\text { Molecular } \\
\text { weight }\end{array}$ & Structure & References \\
\hline $\begin{array}{l}\text { Pegaptanib sodium (Macugen; } \\
\text { Eyetech Pharmaceuticals/Pfizer) }\end{array}$ & 2004 & VEGF165 & $50 \mathrm{kDa}$ & RNA aptamer & VISION 2004 [18] \\
\hline $\begin{array}{l}\text { Bevacizumab } \\
\text { (Avastin; Roche) }\end{array}$ & Off-label & VEGF-A & $149 \mathrm{kDa}$ & $\begin{array}{l}\text { Recombinant humanized } \\
\text { monoclonal antibody }\end{array}$ & $\begin{array}{c}\text { ABC [19] } \\
\text { MANTA [20] }\end{array}$ \\
\hline $\begin{array}{l}\text { Ranibizumab } \\
\text { (Lucentis; Novartis) }\end{array}$ & 2007 & VEGF-A & $48 \mathrm{kDa}$ & $\begin{array}{c}\text { Recombinant humanized } \\
\text { monoclonal antibody } \\
\text { fragment }\end{array}$ & $\begin{array}{l}\text { MARINA [21] } \\
\text { ANCHOR [21] } \\
\text { PIER [22] }\end{array}$ \\
\hline $\begin{array}{l}\text { Aflibercept } \\
\text { (Eylea; Bayer) }\end{array}$ & 2011 & $\begin{array}{c}\text { VEGF-A, } \\
\text { VEGF-B, PIGF }\end{array}$ & $115 \mathrm{kDa}$ & Recombinant protein & $\begin{array}{l}\text { VIEW-1 [23] } \\
\text { VIEW-2 [23] }\end{array}$ \\
\hline $\begin{array}{l}\text { Brolucizumab } \\
\text { (Beovu; Novartis) }\end{array}$ & 2019 & VEGF-A & $26 \mathrm{kDa}$ & $\begin{array}{c}\text { Single-chain } \\
\text { anti-VEGF-A } \\
\text { antibody fragment }\end{array}$ & $\begin{array}{c}\text { HAWK } \\
\text { HARRIER } \\
{[17,24]}\end{array}$ \\
\hline $\begin{array}{l}\text { Abicipar pegol } \\
\text { (Rayocta; Allergan) }\end{array}$ & $\begin{array}{l}\text { Not } \\
\text { registered }\end{array}$ & VEGF-A & $34 \mathrm{kDa}$ & Based on DARPins & $\begin{array}{c}\text { CEDAR }[25,26] \\
\text { SEQUOIA }[25,26] \\
\text { BAMBOO [27] } \\
\text { CYPRESS [27] }\end{array}$ \\
\hline $\begin{array}{l}\text { Faricimab (RG7716) } \\
\text { (Roche/Genentech) }\end{array}$ & $\begin{array}{l}\text { Not } \\
\text { registered }\end{array}$ & $\begin{array}{l}\text { VEGF-A, } \\
\text { Ang-2 }\end{array}$ & $148 \mathrm{kDa}$ & Bispecific antibody & $\begin{array}{l}\text { STAIRWAY [28] } \\
\text { AVENUE [29] }\end{array}$ \\
\hline
\end{tabular}

\section{New anti-VEGF agents in neovascular AMD}

There are current studies developing novel anti-VEGF treatment for wet AMD. One such agent is abicipar pegol. It is the first non-monoclonal antibody protein in the antiVEGF group.

Abicipar pegol has a low molecular weight and no immunoglobulin component. Its structure is based on a repeated sequence of proteins called DARPins: designed ankyrin repeat proteins. DARPins are designed and engineered to bind specifically to a ligand, in this case to VEGF.

In phase 3 trials, CEDAR (NCT02462928) and SEQUOIA (NCT02462486), comparing the effect of abicipar pegol to ranibizumab it was found that it maintained stable vision [25, 26]. Other trials showed longer halflife of abicipar pegol than of aflibercept and ranibizumab (6 days vs. 4.7 days and 2.5 days) [30, 31]. However, its major side effect was intraocular inflammation, probably due to Escherichia coli fragments in its structure, which occurred in $15-16 \%$ of cases according to CEDAR, SEQUOIA and MAPLE trials and 7.5-10.4\% in BAMBOO and CYPRESS trials [30, 32, 33]. Abicipar pegol was not approved for use by the FDA in 2020.

Another novel approach to anti-VEGF treatment includes a bispecific antibody blocking VEGF-A and angiopoietin-2 (Ang-2): faricimab (RG7716). It is an agent developed by Roche/Genentech and administered intravitreally $[33,34]$. The level of Ang-2 is elevated in retinal pathologies, such as CNV formation [35]. Angiopoietin-2 inhibits the Tie 2 receptor, which leads to inhibition of formation of endothelial tight junctions and in effect to leakage in the endothelial cell layer [36]. Thus, blocking Ang-2 results in reducing inflammation and increasing the permeability. The structure of faricimab includes modification of the $\mathrm{Fc}$ fragment that reduces the systemic exposure, which lowers the risk of intraocular inflammation [34]. The anatomical effect, visual acuity outcomes and safety outcomes show faricimab to be non-inferior to ranibizumab, as was proved in the STAIRWAY clinical trial. The endpoints in best-corrected visual acuity and anatomical imaging with optical coherent tomography in faricimab therapy were comparable with ranibizumab [29, 37].

\section{Anti-PDGF therapy in neovascular AMD}

Platelet-derived growth factor has an important role in vascular proliferative retinopathies. Its isoforms, PDGF-A and PDGF-B, both stimulate proliferation, whereas PDGF-B is the molecule responsible for proliferation of vascular and non-vascular cells [38]. Suppression of PDGF-B leads to suppression of choroidal neovascularisation. The combined action of anti-PDGF-B and antiVEGF therapy is more effective than anti-VEGF alone $[14,39]$. Axitinib is a tyrosine kinase inhibitor agent used in renal cancer therapy. Researchers have reported promising potential of combined PDGF and VEGF therapy with axitinib in both in vivo and in vitro models of human endothelial cells [40, 41].

\section{Gene therapy in neovascular AMD}

Gene therapy is experiencing rapid development, which is proved by introduction of Luxturna in 2017. It a drug effective in diseases resulting from mutations in the RPE65 
gene, e.g. Leber congenital amaurosis (LCA) and severe early-childhood-onset retinal degeneration (SECORD). Luxturna was the first ophthalmic gene therapy introduced [42]. Gene therapy is also under investigation in other ocular diseases, such as glaucoma, where experimental therapies on a mouse model show promising effects [43].

Due to the fact that anti-VEGF therapy's effects in AMD do not prove the permanent visual acuity conservation and due to the fact of technical and financial difficulties of anti-VEGF intravitreal injections, there is a strong need to develop gene therapies for nAMD. Authors confirm that the anatomical and immunological features of the human retina make this organ an ideal target for gene therapy [7].

The main way of gene supplementation in ophthalmic research is with the use of either a recombinant adenoassociated viral (AAV) or lentiviral vector delivered preferably subretinally, whereas intravitreal and suprachoroidal administration is also possible [7, 44].

There are two main therapeutic strategies in nAMD: gene silencing and AAV-mediated gene therapy with therapeutic proteins [45].

\section{Gene silencing gene therapy}

Gene-specific therapy targets a specific gene responsible for the pathologic process. It uses site-specific endonucleases in order to excise the faulty gene. The type of endonuclease which is gaining popularity is CRISPR-associated (Cas) systems: the bacteria-derived RNA-guided systems [45, 46]. Currently on-going CRISPR-Cas experiments on AMD target VEGF-A, VEGFR2 and HIF-1 $\alpha$ genes [47, 48].

\section{Virus mediated gene augmentation therapy}

Adeno-associated virus vectors exert low pathogenicity, immunogenicity and capacity for self-replication [45]. The AAV vector carrying pigment epithelium derived factor (PEDF) was proven effective with a dose-related response $[49,50]$. Another possible therapy involves sFLT-1 protein, a VEGF-A inhibitor, and is shown to be safe and well tolerated [51].

The novel approach to gene therapy is presented in therapy with ADVM-022 and RGX-314. ADVM-022 therapy involves one-time intravitreal injection with an AAV encoding aflibercept. The ongoing study is expected to finish in June 2022 [52, 53]. RGX-314 (Regenxbio) therapy involves one-time intravitreal injection with an AAV encoding ranibizumab; the results of a 2-phase study have not been reported yet [54].

Retinostat - a gene therapy with endostatin and angiostatin, involving EIAV (equine infectious anemia virus) - was found to be both safe and effective in inhibiting choroidal neovascularisation [55-57].

Another direction for gene therapy in nAMD is addressing the complement cascade. The studies have shown that complement inhibition reduces CNV formation [58], either in gene therapy models [59] or with the use of monoclonal antibody $[60,61]$.

\section{Dry AMD}

Retinal damage is triggered by factors including aging and environmental stress [5]. Complement is one of the main immunological components in the molecular pathophysiology of the cell degeneration. Complement's role has been proven crucial in retinal ganglion cell death in glaucoma [62] and its deregulation is also underlined as one of the causes of dry AMD formation [63].

The classical complement pathway is triggered by dead or damaged cells tagged by the $\mathrm{C} 1$ complex, which then triggers $\mathrm{C} 3$ convertase. In effect, $\mathrm{C} 3$ converts into $\mathrm{C} 3 \mathrm{a}$ (anaphylatoxin) and $\mathrm{C} 3 \mathrm{~b}$ (opsonin). $\mathrm{C} 3 \mathrm{a}$ activates $\mathrm{C} 5$ convertase, which triggers the conversion of $\mathrm{C} 5$ into $\mathrm{C} 5 \mathrm{a}$ (anaphylatoxin, chemotactic factor) and $\mathrm{C} 5 \mathrm{~b}$ (the first part of the membrane attacking complex - MAC). MAC formation leads to cell lysis. Complement's other function is to enable opsonization, which leads to further phagocytosis [63, 64].

Component factor $\mathrm{H}(\mathrm{CFH})$ and complement factor I (CFI) are proteins triggering the alternative complement pathway and activating C3 convertase. The complement cascade results in MAC formation.

MAC plays the role of the effector of the complement cascade in cell death. Studies have shown its presence in aging maculae considered healthy. It has been found in higher concentrations starting from the age of 50 as well as in patients with AMD [58].

CFI inhibitors inactivate $\mathrm{C} 3 \mathrm{~b}$, preventing MAC formation on the host cell surface [58]. CFH inhibits activation of the alternative complement pathway. Certain types of mutation of the $\mathrm{CFH}$ gene result in a higher MAC concentration in the macula and are considered the strongest genetic risk factors for AMD $[63,65,66]$. The effect of MAC on retinal vessels' epithelium is the loss of choroidal vasculature, which leads to formation of atrophic regions [58].

\section{Complement inhibitor antibodies in dry AMD}

Eculizumab is an antibody inhibiting complement component $\mathrm{C} 5$ and lampalizumab is an antibody inhibiting complement factor D [67-69]. The primary results of the trials with complement inhibitors raised high hopes for its future impact on dry AMD successful therapy. Lampalizumab, however, did not reduce the enlargement of geographical atrophy in randomized clinical trials [68, 69].

Pegcetacoplan (APL-2) is an anti-C3 antibody. Avacincaptad pegol (Zimura) is an anti-C5 antibody. There are studies reporting significant reduction of the GA growth rate by intravitreal administration of APL-2 and Zimura. However, patients receiving these agents presented 3 to 
17 times higher risk of developing nAMD [66, 70, 71]. Another trial examined monoclonal anti-amyloid- $\beta$ therapy intravenously and proved no significant effect of the agent [72]. Possible future therapies targeting CFH, CFI and MAC are under investigation [73].

\section{Gene therapy in dry AMD}

The complement cascade targeted gene therapy was supposed to be effective in dry AMD. However, recently there have been few reports providing significant results of these therapies. The designed gene therapies focused on the complement cascade. One of the agents augmented the expression of protein CD59. Its mechanism protects RPE cells by CD59-mediated inhibition of the membrane attacking complex $[74,75]$.

\section{Other therapies in dry AMD}

Due to the need for more effective solutions in dry AMD treatment, there are many ways to approach the disease under study. Jaffe et al. examined tandospirone administered topically, with no significant result [76]. Lutein together with other antioxidative agents such as zeaxanthin and fatty acids was proven to play a role in retinal protection in AMD [77-79]. A study on emixustat hydrochloride resulted in no reduction of AMD progression [80]. The most recent reports showed no benefits of oral administration of alpha lipoic acid (ALA) on GA formation inhibition [81].

\section{Conclusions}

The treatment of AMD became more successful in the recent decades as anti-VEGF treatment became introduced on a large scale. There is more impact put on the prevention of the disease and early diagnosis. Neovascular AMD therapy still lacks long-lasting and easier to administer therapies.

Still, there is a high need for developing new agents preventing macular atrophy formation. The complement cascade inhibitors trials have not been proven effective so far, but still new agents are being examined.

\section{The authors declare no conflict of interest.}

\section{References}

1. GBD 2019 Blindness and Vision Impairment Collaborators, et al. (2019): Causes of blindness and vision impairment in 2020 and trends over 30 years, and prevalence of avoidable blindness in relation to VISION 2020: the Right to Sight: an analysis for the Global Burden of Disease Study. Lancet Glob Health 2021; 9: e144-e160. Erratum in: Lancet Glob Health 2021; 9: e408.

2. Klein R, Meuer SM, Myers CE, et al. (2014): Harmonizing the classification of age-related macular degeneration in the three-continent AMD consortium. Ophthalmic Epidemiol 2014; 2: 14-23.

3. Mitchell P, Liew G, Gopinath B, Wong TY (2018): Age-related macular degeneration. Lancet 2018; 392: 1147-1159.

4. McLeod DS, Grebe R, Bhutto I, et al. (2009): Relationship between RPE and choriocapillaris in age-related macular degeneration. Invest Ophthalmol Vis Sci 2009; 50: 4982-4991.

5. Boyer DS, Schmidt-Erfurth U, van Lookeren Campagne M, et al. (2017): The pathophysiology of geographic atrophy secondary to age-related macular degeneration and the complement pathway as a therapeutic target. Retina 2017; 37: 819-835.

6. Radomska-Leśniewska DM, Bałan BJ, Skopiński P (2017): Angiogenesis modulation by exogenous antioxidants. Cent Eur J Immunol 2017; 42: 370-376.

7. Guimaraes TAC, Georgiou M, Bainbridge JWB, Michaelides M (2021): Gene therapy for neovascular age-related macular degeneration: rationale, clinical trials and future directions. $\mathrm{Br}$ J Ophthalmol 2021; 105: 151-157.

8. Bressler NM. Treatment of Age-Related Macular Degeneration with Photodynamic Therapy (TAP) Study Group (2001): Photodynamic therapy of subfoveal choroidal neovascularization in age-related macular degeneration with verteporfin: two-year results of 2 randomized clinical trials-tap report 2. Arch Ophthalmol 2001; 119: 198-207.

9. Chan WM, Lim TH, Pece A, et al. (2010): Verteporfin PDT for non-standard indications - a review of current literature. Graefes Arch Clin Exp Ophthalmol 2010; 248: 613-626.

10. Lim TH, Lai TYY, Takahashi K, et al. (2020): Comparison of ranibizumab with or without verteporfin photodynamic therapy for polypoidal choroidal vasculopathy: the EVEREST II randomized clinical trial. JAMA Ophthalmol 2020; 138: 935-942.

11. Gunaydin G, Gedik ME, Ayan S (2021): Photodynamic therapy-current limitations and novel approaches. Front Chem 2021; 9: 691-697.

12. Ghodasra DH, Demirci H (2016): Photodynamic therapy for choroidal metastasis. Am J Ophthalmol 2016; 161: 104-109. e1-2.

13. Fogli S, Del Re M, Rofi E, et al. (2018): Clinical pharmacology of intravitreal anti-VEGF drugs. Eye (Lond) 2018; 32: 1010-1020.

14. Campochiaro PA (2015): Molecular pathogenesis of retinal and choroidal vascular diseases. Prog Retin Eye Res 2015; 49: 67-81.

15. Chalam KV, Brar VS, Murthy RK (2014): Human ciliary epithelium as a source of synthesis and secretion of vascular endothelial growth factor in neovascular glaucoma. JAMA Ophthalmol 2014; 132: 1350-1354.

16. Heier JS, Brown DM, Chong V, et al. (2012): Intravitreal aflibercept (VEGF trap-eye) in wet age-related macular degeneration. Ophthalmology 2012; 119: 2537-2548. Erratum in: Ophthalmology 2013; 120: 209-210.

17. Dugel PU, Koh A, Ogura Y, et al. (2020): HAWK and HARRIER: phase 3, multicenter, randomized, double-masked trials of brolucizumab for neovascular age-related macular degeneration. Ophthalmology 2020; 127: 72-84.

18. D'Amico DJ, Bird AC (2004): VEGF Inhibition Study in Ocular Neovascularization-1 (VISION-1): safety evaluation from the pivotal Macugen ${ }^{\circledR}$ (pegaptanib sodium) clinical trials. Invest Ophthalmol Vis Sci 2004; 45: ARVO.

19. Patel PJ, Henderson L, Sivaprasad S, et al. (2007): The ABC trial - a randomized double-masked phase III study of the efficacy and safety of Avastin ${ }^{\circledR}$ (Bevacizumab) intravitreal injections compared to standard therapy in subjects with choroidal neovascularization secondary to age-related macular 
degeneration (AMD). Invest Ophthalmol Vis Sci 2007; 48: ARVO.

20. Krebs I, Schmetterer L, Boltz A, et al. (2013): A randomised double-masked trial comparing the visual outcome after treatment with ranibizumab or bevacizumab in patients with neovascular age-related macular degeneration. Br J Ophthalmol 2013; 97: 266-271.

21. Ciulla TA, Shapiro H, Schneider S (2007): Ranibizumab (Lucentis $\left.{ }^{\circledR}\right)$ for neovascular age-related macular degeneration (AMD): 1-year visual acuity (VA) results for fellow eyes with neovascular AMD in MARINA and ANCHOR. Invest Ophthalmol Vis Sci 2007; 48: ARVO.

22. Regillo CD, Brown DM, Abraham P, et al. (2008): Randomized, double-masked, sham-controlled trial of ranibizumab for neovascular age-related macular degeneration: PIER Study year 1. Am J Ophthalmol 2008; 145: 239-248.

23. Schmidt-Erfurth U, Kaiser PK, Korobelnik JF, et al. Intravitreal aflibercept injection for neovascular age-related macular degeneration: ninety-six-week results of the VIEW studies. Ophthalmology 2014; 121: 193-201.

24. Dugel PU, Singh RP, Koh A, et al. (2020): HAWK and HARRIER: ninety-six-week outcomes from the phase 3 trials of brolucizumab for neovascular age-related macular degeneration. Ophthalmology 2021; 128: 89-99.

25. Kunimoto D, Yoon YH, Wykoff CC, et al. (2020): CEDAR and SEQUOIA Study Groups. Efficacy and safety of abicipar in neovascular age-related macular degeneration: 52 -week results of phase 3 randomized controlled study. Ophthalmology 2020; 127: 1331-1344.

26. Khurana RN, Kunimoto D, Yoon YH, et al. (2021): CEDAR and SEQUOIA Study Groups. Two-year results of the phase 3 randomized controlled study of abicipar in neovascular age-related macular degeneration. Ophthalmology 2021; 128 : 1027-1038.

27. Kunimoto D, Ohji M, Maturi RK, et al. (2019): Evaluation of abicipar pegol (an anti-VEGF DARPin therapeutic) in patients with neovascular age-related macular degeneration: studies in Japan and the United States. Ophthalmic Surg Lasers Imaging Retina 2019; 50: e10-e22.

28. Khanani AM, Patel SS, Ferrone PJ, et al. (2020): Efficacy of every four monthly and quarterly dosing of faricimab vs ranibizumab in neovascular age-related macular degeneration: The STAIRWAY phase 2 randomized clinical trial [published correction appears in JAMA Ophthalmol. 2020 Sep 1;138(9):1006]. JAMA Ophthalmol 2020; 138: 964-972.

29. Sahni J, Dugel PU, Patel SS, et al. (2020): Safety and efficacy of different doses and regimens of faricimab vs ranibizumab in neovascular age-related macular degeneration: the AVENUE phase 2 randomized clinical trial. JAMA Ophthalmol 2020; 138: 955-963.

30. Sharma A, Kumar N, Kuppermann BD, Bandello F (2020): Abicipar pegol: the non-monoclonal antibody anti-VEGF. Eye (Lond) 2020; 34: 797-801.

31. Campochiaro PA, Channa R, Berger BB, et al. (2013): Treatment of diabetic macular edema with a designed ankyrin repeat protein that binds vascular endothelial growth factor: a phase I/II study. Am J Ophthalmol 2013; 155: 697-704, 704. e1-2.

32. Allergan and Molecular Partners Announce Topline Safety Results from MAPLE study of Abicipar pegol. Available at: https://www.molecularpartners.com/allergan-and-molecular-partners-announce-topline-safety-results-from-maple-study-of-abicipar-pegol/.

33. Samanta A, Aziz AA, Jhingan M, et al. (2020): Emerging therapies in neovascular age-related macular degeneration in 2020. Asia Pac J Ophthalmol (Phila) 2020; 9: 250-259.
34. Chakravarthy U, Bailey C, Brown D, et al. (2017): Phase I trial of anti-vascular endothelial growth factor/anti-angiopoietin 2 bispecific antibody RG7716 for neovascular age-related macular degeneration. Ophthalmol Retina 2017; 1: 474-485.

35. Hackett SF, Ozaki H, Strauss RW, et al. (2000): Angiopoietin 2 expression in the retina: upregulation during physiologic and pathologic neovascularization. J Cell Physiol 2000; 184: 275-284.

36. Augustin HG, Koh GY, Thurston G, Alitalo K (2009): Control of vascular morphogenesis and homeostasis through the angiopoietin-Tie system. Nat Rev Mol Cell Biol 2009; 10: 165-177.

37. Khanani AM, Patel SS, Ferrone PJ, et al. (2020): Efficacy of every four monthly and quarterly dosing of faricimab vs ranibizumab in neovascular age-related macular degeneration: The STAIRWAY phase 2 randomized clinical trial [published correction appears in JAMA Ophthalmol. 2020;138(9):1006]. JAMA Ophthalmol 2020; 138: 964-972.

38. Mori K, Gehlbach P, Ando A, et al. (2002): Retina-specific expression of PDGF-B versus PDGF-A: vascular versus nonvascular proliferative retinopathy. Invest Ophthalmol Vis Sci 2002; 43: 2001-2006.

39. Boyer DS, the Ophthotech Anti-PDGF in AMD Study Group (2009): Combined inhibition of platelet-derived (PDGF) and vascular endothelial (VEGF) growth factors for the treatment of neovascular age-related macular degeneration (NV-AMD). Results of a phase 1 study. Invest Ophthalmol Vis Sci 2009 Online ARVO abstract 1260.

40. Siedlecki J, Wertheimer C, Wolf A, et al. (2017): Combined VEGF and PDGF inhibition for neovascular AMD: anti-angiogenic properties of axitinib on human endothelial cells and pericytes in vitro. Graefes Arch Clin Exp Ophthalmol 2017; 255: 963-972.

41. Giddabasappa A, Lalwani K, Norberg R, et al. (2016): Axitinib inhibits retinal and choroidal neovascularization in in vitro and in vivo models. Exp Eye Res 2016; 145: 373-379.

42. Weleber RG, Pennesi ME, Wilson DJ, et al. (2016): Results at 2 years after Gene Therapy for RPE65-Deficient Leber Congenital Amaurosis and Severe Early-Childhood-Onset Retinal Dystrophy. Ophthalmology 2016; 123: 1606-1620.

43. Skopiński P, Radomska-Leśniewska DM, Izdebska J, et al. (2021): New perspectives of immunomodulation and neuroprotection in glaucoma. Cent Eur J Immunol 2021; 46: 105110.

44. Koponen S, Kokki E, Kinnunen K, Ylä-Herttuala S (2021): Viral-vector-delivered anti-angiogenic therapies to the eye. Pharmaceutics 2021; 13: 219.

45. Lin FL, Wang PY, Chuang YF, et al. (2020): Gene therapy intervention in neovascular eye disease: a recent update. Mol Ther 2020; 28: 2120-2138.

46. Guha TK, Wai A, Hausner G (2017): Programmable genome editing tools and their regulation for efficient genome engineering. Comput Struct Biotechnol J 2017; 15: 146-160.

47. Kim E, Koo T, Park SW, et al. (2017): In vivo genome editing with a small Cas9 orthologue derived from Campylobacter jejuni. Nat Commun 2017; 8: 14500.

48. Yu W, Mookherjee S, Chaitankar V, et al. (2017): Nrl knockdown by AAV-delivered CRISPR/Cas9 prevents retinal degeneration in mice. Nat Commun 2017; 8: 14716.

49. Campochiaro PA, Nguyen QD, Shah SM, et al. (2006): Adenoviral vector-delivered pigment epithelium-derived factor for neovascular age-related macular degeneration: results of a phase I clinical trial. Hum Gene Ther 2006; 17: 167-176.

50. Rasmussen H, Chu KW, Campochiaro PA, et al. (2001): Clinical protocol. An open-label, phase I, single administration, dose-escalation study of ADGVPEDF.11D (ADPEDF) in 
neovascular age-related macular degeneration (AMD). Hum Gene Ther 2001; 12: 2029-2032.

51. Heier JS, Kherani S, Desai S, et al. (2017): Intravitreous injection of AAV2-sFLT01 in patients with advanced neovascular age-related macular degeneration: a phase 1, open-label trial. Lancet 2017; 390: 50-61.

52. Grishanin R, Vuillemenot B, Sharma P, et al. (2018): Preclinical evaluation of ADVM-022, a novel gene therapy approach to treating wet age-related macular degeneration. Mol Ther 2019; 27: 118-129.

53. ADVM-022 Intravitreal Gene Therapy for Wet AMD (OPTIC), available at: https://clinicaltrials.gov/ct2/show/ NCT03748784?term $=$ advm- $022 \&$ draw $=2 \&$ rank $=2$

54. RGX-314 Gene Therapy Administered in the Suprachoroidal Space for Participants With Neovascular Age-Related Macular Degeneration (nAMD) (AAVIATE), available at: https:// clinicaltrials.gov/ct2/show/study/NCT04514653?term=regenxbio\&draw $=2 \&$ rank $=9$

55. Binley K, Widdowson PS, Kelleher M, et al. (2012): Safety and biodistribution of an equine infectious anemia virus-based gene therapy, RetinoStat( $\left({ }^{\circledR}\right)$, for age-related macular degeneration. Hum Gene Ther 2012; 23: 980-991.

56. Campochiaro PA, Lauer AK, Sohn EH, et al. (2017): Lentiviral vector gene transfer of endostatin/angiostatin for macular degeneration (GEM) study. Hum Gene Ther 2017; 28: 99-111.

57. Kachi S, Binley K, Yokoi K, et al. (2009): Equine infectious anemia viral vector-mediated codelivery of endostatin and angiostatin driven by retinal pigmented epithelium-specific VMD2 promoter inhibits choroidal neovascularization. Hum Gene Ther 2009; 20: 31-39.

58. Whitmore SS, Sohn EH, Chirco KR, et al. (2015): Complement activation and choriocapillaris loss in early AMD: Implications for pathophysiology and therapy. Prog Retin Eye Res 2015; 45: 1-29.

59. Birke MT, Lipo E, Adhi M, et al. (2014): AAV-mediated expression of human PRELP inhibits complement activation, choroidal neovascularization and deposition of membrane attack complex in mice. Gene Ther 2014; 21: 507-513.

60. Rohrer B, Coughlin B, Bandyopadhyay M, Holers VM (2012): Systemic human CR2-targeted complement alternative pathway inhibitor ameliorates mouse laser-induced choroidal neovascularization. J Ocul Pharmacol Ther 2012; 28: 402-409.

61. Lipo E, Cashman SM, Kumar-Singh R (2013): Aurintricarboxylic acid inhibits complement activation, membrane attack complex, and choroidal neovascularization in a model of macular degeneration. Invest Ophthalmol Vis Sci 2013; 54: 7107-7114.

62. Samelska K, Zaleska-Żmijewska A, Bałan B, et al. Immunological and molecular basics of the primary open angle glaucoma pathomechanism. Cent Eur J Immunol 2021; 46: 111-117.

63. van Lookeren Campagne M, Strauss EC, Yaspan BL (2016): Age-related macular degeneration: Complement in action. Immunobiology 2016; 221: 733-739.

64. Williams PA, Tribble JR, Pepper KW, et al. (2016): Inhibition of the classical pathway of the complement cascade prevents early dendritic and synaptic degeneration in glaucoma. Mol Neurodegener 11: 26.

65. Mullins RF, Dewald AD, Streb LM, et al. (2011): Elevated membrane attack complex in human choroid with high risk complement factor H genotypes. Exp Eye Res 2011; 93: 565-567.
66. Lin JB, Halawa OA, Miller JW, Vavvas DG (2021): Complement inhibition for geographic atrophy: a tempting target with mixed results. J Clin Med 2021; 10: 2890.

67. Akyol E, Lotery A (2020): Gene, cell and antibody-based therapies for the treatment of age-related macular degeneration. Biologics 2020; 14: 83-94.

68. Yehoshua Z, de Amorim Garcia Filho CA, Nunes RP, et al. (2014): Systemic complement inhibition with eculizumab for geographic atrophy in age-related macular degeneration: the COMPLETE study. Ophthalmology 2014; 121: 693-701.

69. Holz FG, Sadda SR, Busbee B, et al. (2018): Chroma and Spectri Study Investigators. Efficacy and safety of lampalizumab for geographic atrophy due to age-related macular degeneration: chroma and Spectri phase 3 randomized clinical trials. JAMA Ophthalmol 2018; 136: 666-677.

70. Liao DS, Grossi FV, El Mehdi D, et al. (2020): Complement C3 inhibitor pegcetacoplan for geographic atrophy secondary to age-related macular degeneration. Ophthalmology 2020; 127: $186-195$

71. Jaffe GJ, Westby K, Csaky KG, et al. (2021): C5 Inhibitor avacincaptad pegol for geographic atrophy due to age-related macular degeneration. Ophthalmology 2021; 128: 576-586.

72. Rosenfeld PJ, Berger B, Reichel E, et al. (2018): A randomized phase 2 study of an anti-amyloid $\beta$ monoclonal antibody in geographic atrophy secondary to age-related macular degeneration. Ophthalmol Retina 2018; 2: 1028-1040.

73. Halawa OA, Lin JB, Miller JW, Vavvas DG (2021): A review of completed and ongoing complement inhibitor trials for geographic atrophy secondary to age-related macular degeneration. J Clin Med 2021; 10: 2580.

74. Ramo K, Cashman SM, Kumar-Singh R (2008): Evaluation of adenovirus-delivered human CD59 as a potential therapy for AMD in a model of human membrane attack complex formation on murine RPE. Invest Ophthalmol Vis Sci 2008; 49: 4126-4136.

75. Leaderer D, Cashman SM, Kumar-Singh R (2015): Adeno-associated virus mediated delivery of an engineered protein that combines the complement inhibitory properties of CD46, CD55 and CD59. J Gene Med 2015; 17: 101-115.

76. Jaffe GJ, Schmitz-Valckenberg S, Boyer D, et al. (2015): Randomized trial to evaluate tandospirone in geographic atrophy secondary to age-related macular degeneration: the GATE study. Am J Ophthalmol 2015; 160: 1226-1234.

77. Lem DW, Davey PG, Gierhart DL, Rosen RB (2021): A systematic review of carotenoids in the management of age-related macular degeneration. Antioxidants (Basel) 2021; 10: 1255.

78. Age-Related Eye Disease Study Research Group (2000): Risk factors associated with age-related macular degeneration. A case-control study in the age-related eye disease study: Age-Related Eye Disease Study Report Number 3. Ophthalmology 2000; 107: 2224-2232.

79. Age-Related Eye Disease Study 2 Research Group (2013): Lutein + zeaxanthin and omega-3 fatty acids for age-related macular degeneration: the Age-Related Eye Disease Study 2 (AREDS2) randomized clinical trial. JAMA 2013; 309: 20052015.

80. Rosenfeld PJ, Dugel PU, Holz FG, et al. (2018): Emixustat hydrochloride for geographic atrophy secondary to age-related macular degeneration: a randomized clinical trial. Ophthalmology 2018; 125: 1556-1567.

81. Kim BJ, Hunter A, Brucker AJ, et al. (2020): Orally administered alpha lipoic acid as a treatment for geographic atrophy: a randomized clinical trial. Ophthalmol Retina 2020; 4: 889898. 